\title{
Congenital giant Bednar tumor in a child: surgical challenges in a young infant: a case report
}

\author{
Vidhya Gunasekaran, Nitin J. Peters ${ }^{*}$ (i) and Ram Samujh
}

\begin{abstract}
Background: Bednar tumor is a pigmented variant of the uncommon dermatofibrosarcoma protuberans (DFSP). It is a disease of the middle aged and elderly and has been rarely described in the pediatric population.

Case presentation: We report a rare case of a giant Bednar tumor present since birth, in a 2-year-old male child. It was present over the lower back and managed by surgical excision.

Conclusions: Bednar tumor is a rarity in children and is managed with aggressive wide local excision with margin of at least $1 \mathrm{~cm}$. A close clinical follow-up is mandatory.
\end{abstract}

Keywords: Bednar tumor, Dermatofibrosarcoma protuberans pediatric

\section{Background}

Bednar tumor is a rare variant of dermatofibrosarcoma protuberans (DFSP) with an incidence of approximately $1-5 \%$ of all cases of DFSP [1]. It is a skin tumor of intermediate grade with limited potential for metastasis and high rate of recurrence. It occurs mainly in early adulthood or middle age, but cases are rarely reported in the pediatric population [1]. The diagnosis and management remain challenging in children. We report a case of a giant congenital Bednar tumor and discuss the surgical management and review of literature. We have adhered to the CARE guidelines while reporting this case.

\section{Case presentation}

A 2-year-old male child, presented with history of painless, pigmented, progressive, slow growing mass over the lumbosacral region since birth. There was no associated history of failure to thrive, fever, or trauma. The lower limbs movements were normal. There was no neurological deficit in bladder and bowel function. General

\footnotetext{
* Correspondence: nitinjamespeters@yahoo.com

Presentation at a meeting: Presented at Indian Association of Pediatric

Surgeons Annual Conference in 2018

Department of Pediatric Surgery, PGIMER, Chandigarh, India
}

physical examination was unremarkable. Local examination showed an exophytic firm to hard bosselated mass, 8 $\times 7 \mathrm{~cm}$ over the lumbosacral region. The mass was deeply pigmented and had hair growth over it (Fig. 1a). This lesion was freely mobile over the underlying muscles. There was no discharge or ulceration over the lesion. No regional lymphadenopathy could be appreciated. Two smaller superficial pigmented satellite skin patches $(1 \times 3$ $\mathrm{cm}$ ) were present over the back and thigh.

Magnetic resonance imaging of the lesion revealed a heterogenous subcutaneous soft tissue sacral mass, likely soft tissue sarcoma (Fig. 2a, b). Fine needle aspiration cytology of the lesion was suggestive of pigmented variant of dermatofibrosarcoma protuberans.

Surgical excision was planned under general anaesthesia. The patient was placed in prone position. Complete tumor excision was done with a $2 \mathrm{~cm}$ clear margin. No macroscopic residual tumor was left behind. The large defect was closed with local rotation skin flap under mild tension. The other two lesions were excised in a second setting (Fig. 1b).

Cut surface of the tumor was dark drown, hairy, encapsulated, with firm to hard consistency. Histopathology of the lesion revealed spindle cells in storiform

\section{Springer Open}

(ㅇ The Author(s). 2020 Open Access This article is licensed under a Creative Commons Attribution 4.0 International License, which permits use, sharing, adaptation, distribution and reproduction in any medium or format, as long as you give appropriate credit to the original author(s) and the source, provide a link to the Creative Commons licence, and indicate if changes were made. The images or other third party material in this article are included in the article's Creative Commons licence, unless indicated otherwise in a credit line to the material. If material is not included in the article's Creative Commons licence and your intended use is not permitted by statutory regulation or exceeds the permitted use, you will need to obtain permission directly from the copyright holder. To view a copy of this licence, visit http://creativecommons.org/licenses/by/4.0/. 


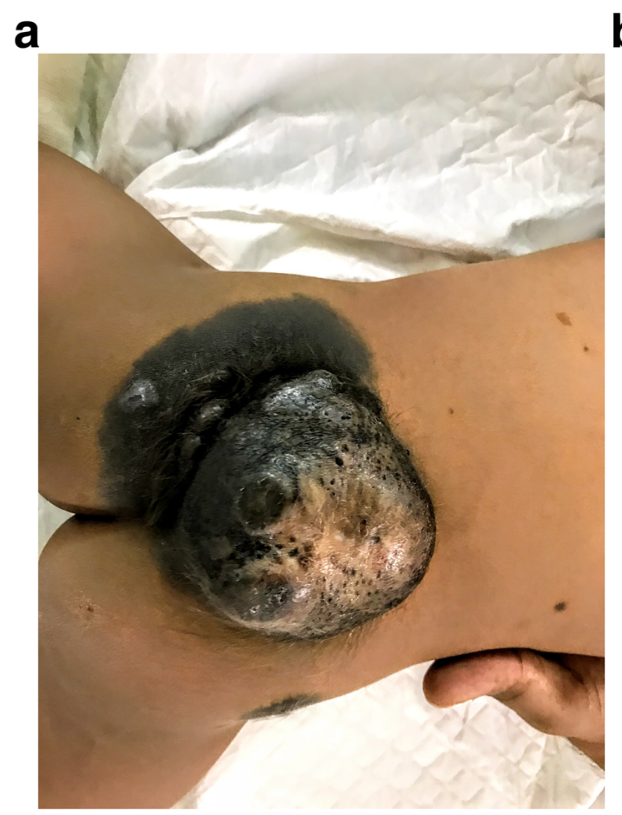

\section{b}

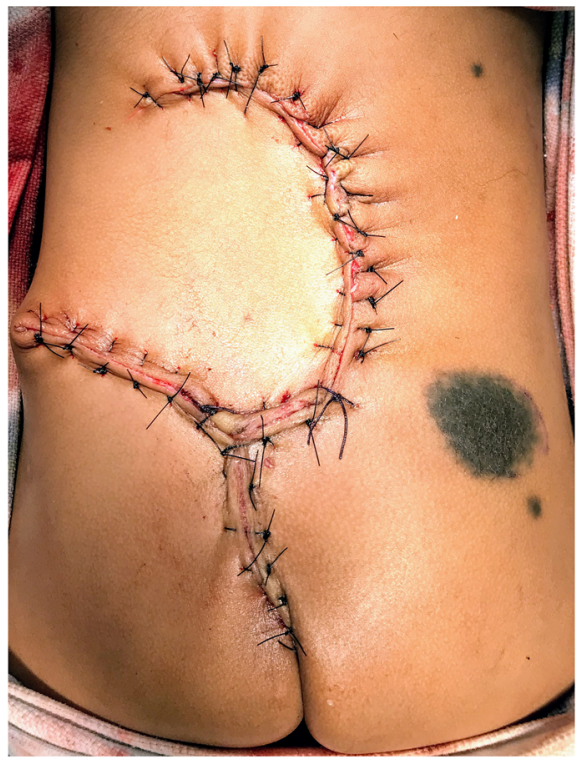

Fig. 1 a Pigmented soft tissue tumor in the lumbosacral region. b Rotational flap cover over the tumor bed after complete excision

pattern which were pleomorphic. Melanin was present in most of the cell with 1-3 mitosis/10 hpf. Immunohistochemistry was suggestive of spindle cells positive for CD34 and negative for CD68 and S-100. Margins were free of the tumor. The post-operative period was uneventful other than superficial wound dehiscence, which was managed by dressings alone. It healed successfully by secondary intention (Fig. 3). The patient is doing well for 2 years with no recurrence. Parental consent was availed for this research publication.

\section{Discussion}

In 1957, Bednar first described a group of nine cutaneous tumors that were characterized by indolent growth and a prominent storiform pattern, and in four cases by the presence of melanin pigment. He regarded these

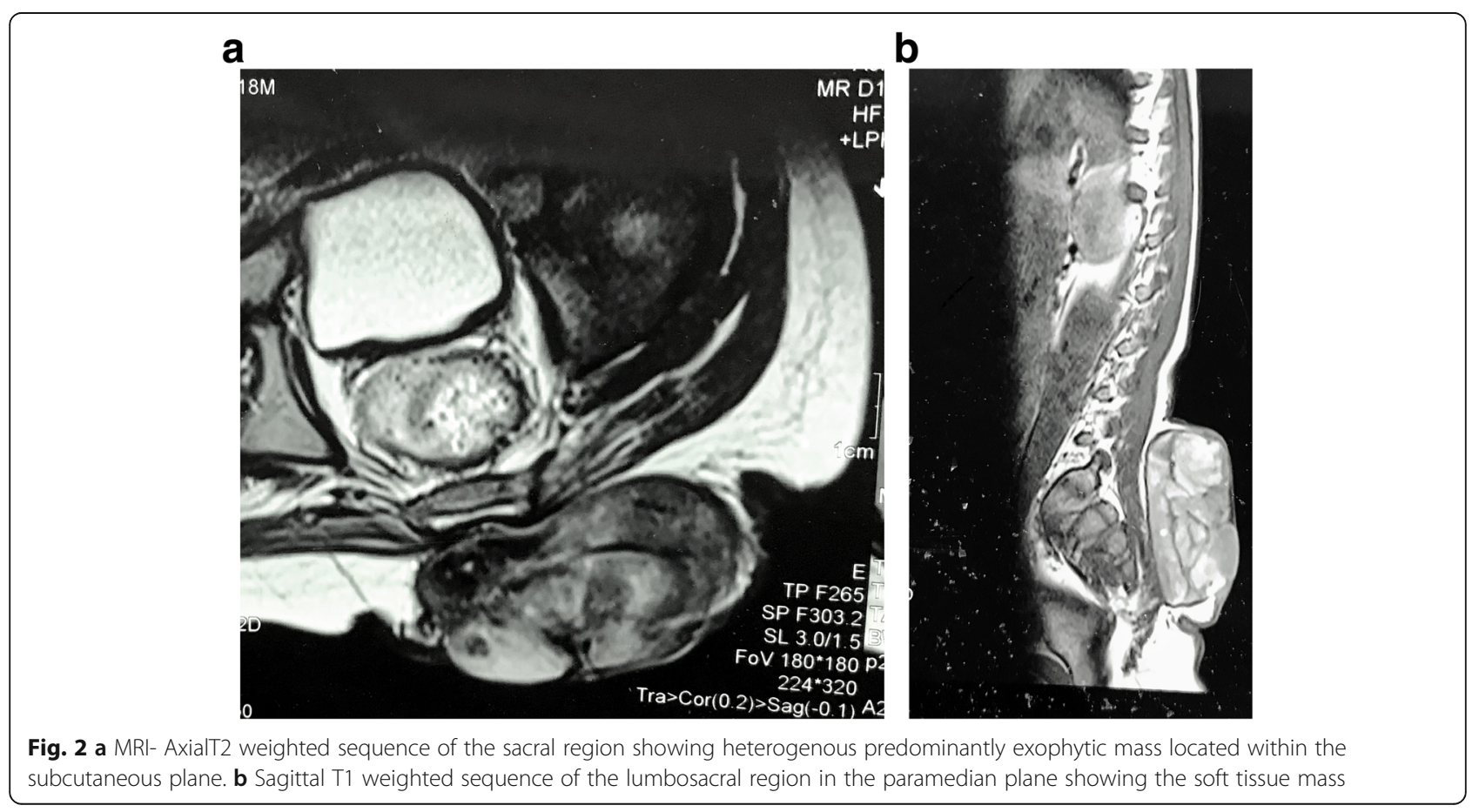




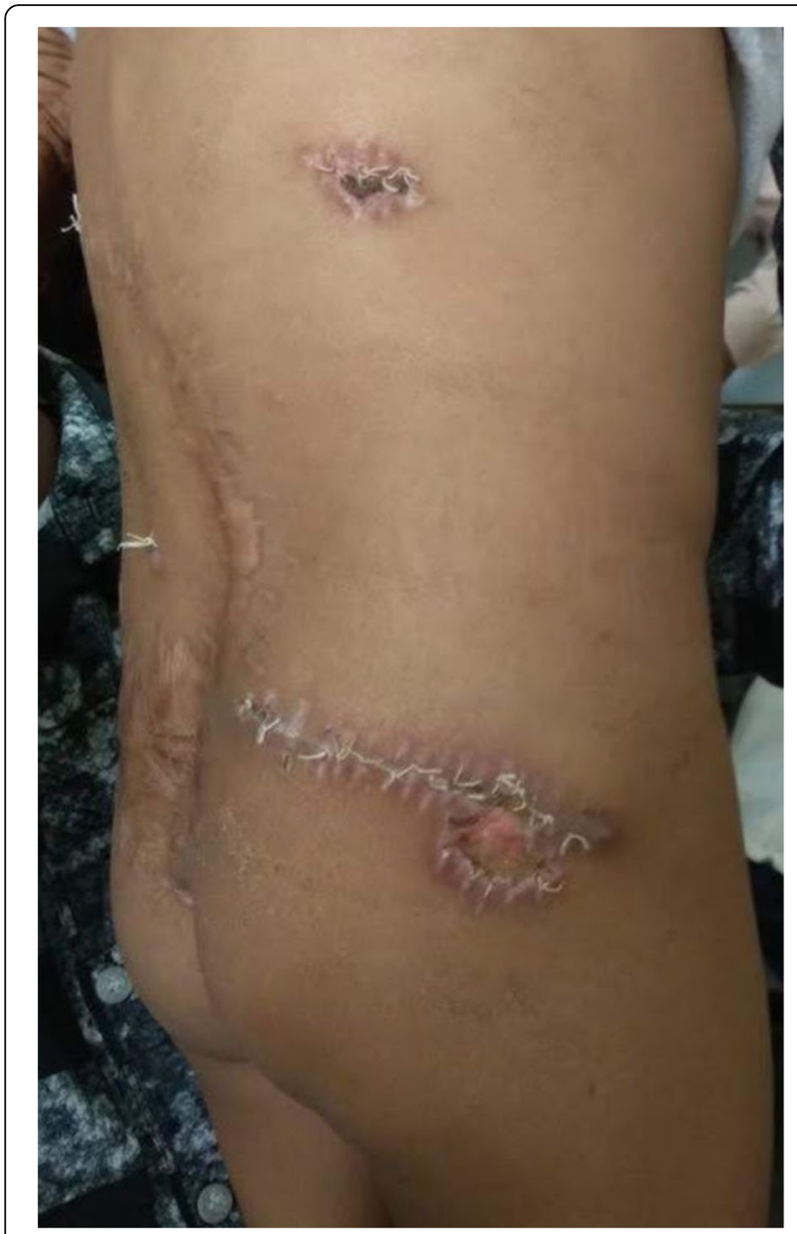

Fig. 3 Follow up image after excision of the secondary lesion showing healed scar tumors as a variant of neurofibromas (storiform neurofibroma) [1]. Bednar tumor is a variant of DFSP containing abundant melanotic pigment. It is a disease of middle age third and fourth decade and is rarely described in children and even rarely in neonates (congenital variant) $[2,3]$. Our case was peculiar, as the parents had noted the pigmentation since birth and was diagnosed as Bednar tumor at the time of presentation to the hospital.

They usually present as slow growing, pigmented lesion most frequently located in the trunk especially the back and shoulder. Morphologically as plaque like lesions of an erythematous-bluish or brownish color, with a smooth or irregular surface. The lesions are rarely exophytic like in our case and are nodular, multi-lobular, and of firm consistency. The tumor has a great potential for locally invasiveness and may reach the subcutaneous strata, fascia, and musculature, in a manner similar to that of DFSP making it prone for recurrence. Metastasis is rare and late and dissemination may occur via the hematogenous route and rarely lymphatic. The principle sites of metastasis are in the lungs, bones, liver, pancreas, stomach, intestine, thyroid, and brain.

The tumor needs to be differentiated from other pigmented lesions like fibrosarcoma, pigmented neurofibroma, melanotic schwannoma, desmoplastic (neurotrophic) melanoma. Bednar tumor is characterized histologically by scattered melanosome-containing dendritic cells in the background of spindle-shaped cells resembling fibroblasts arranged in a storiform pattern. Immunohistochemistry is confirmative for diagnosis [3]. Spindle-shaped tumor cells would be positive for CD34 and vimentin, but negative for S-100 protein and desmin; however, the pigmented cells would be positive for S-100 protein and negative for CD34 [3].

Surgical principle includes complete excision and clear base of the tumour. Most of the times it leaves a large defect requiring flap cover. Mohs's micrographic surgery is the alternative treatment of choice, avoiding excessive excision in critical locations like head or hand; however, this may not be readily available $[4,5]$, leaving behind positive margins or base make the disease prone for recurrence. Wide local excision with 2 to $3 \mathrm{~cm}$ margin involving visibly uninvolved tissue may be difficult in infants and young children. We achieved a R0 resection with aggressive surgical excision and local rotational flap for coverage. A close follow-up to detect recurrences early is important [6]. Malignant transformation to fibrosarcoma with repeated recurrences may occur [7]. Since the lymph node metastasis is rare, lymph node dissection is not necessary.

We recommend a six monthly follow-up for at least 5 years after excision, even though reports of recurrence after two decades are available in literature.

\section{Conclusions}

Bednar is a rare and relatively less aggressive variant of DFSP, with intermediate grade malignant potential. It is uncommon in the pediatric population and rarely reported in the neonatal period and infancy. Complete surgical excision with wide local margins is curative. Local or vascularized flaps are usually required for managing large defects. Close clinical and radiological vigilance is recommended for early detection of local recurrence after surgical excision.

\section{Acknowledgements}

The parents of the patient who consented for use of clinical photographs for publication and research process.

\section{Authors' contributions}

NJP operated the patient, literature review, manuscript writing and editing concept design. VG manuscript writing and literature review. RS concept design, manuscript review. All authors have read and approved the manuscript. 


\section{Availability of data and materials}

NA

Ethics approval and consent to participate

NA

\section{Consent for publication}

Yes, we have written consent from the parents of the patient for including

his data in the case report.

\section{Competing interests}

All authors declare that they have no competing interests.

Received: 23 May 2020 Accepted: 6 October 2020

Published online: 16 November 2020

\section{References}

1. Bednar B. Storiform neurofibromas of the skin, pigmented and nonpigmented. Cancer. 1957;10:368-76.

2. Kaburagi Y, Hatta N, Kawara S, Takehara K. Pigmented dermatofibrosarcoma protuberans (Bednar tumor) occurring in a Japanese infant. Dermatology. 1998;197:48-51.

3. Patil P, Tambe S, Nayak C, Ramya C. Dermatofibrosarcoma protuberans in a 9-year-old child. Indian Dermatol Online J. 2017;8(3):195-7. https://doi.org/ 10.4103/idoj.IDOJ51_16 PMID: 28584757; PMCID: PMC5447340.

4. Kaul R, Kaur N, Dogra SS, Chander B. Variant of dermatofibrosarcoma protuberans: Bednar tumor. Indian J Dermatol. 2015;60(1):107.

5. Wiesmueller F, Agaimy A, Perrakis A, Arkudas A, Horch RE, Grützmann R, Vassos N. Dermatofibrosarcoma protuberans: surgical management of a challenging mesenchymal tumor. World J Surg Oncol. 2019;17(1):90.

6. Eom DW, Kang GH, Lee KW, Choi SJ. Pediatric pigmented dermatofibrosarcoma protuberans (Bednar Tumor): a case report. Korean J Pathol. 2007:41(3):183-6.

7. Suehara Y, Yazawa Y, Hitachi K. Metastatic Bednar tumor (pigmented dermatofibrosarcoma protuberans) with fibrosarcomatous change: a case report. J Orthop Sci. 2004;9:662-5.

\section{Publisher's Note}

Springer Nature remains neutral with regard to jurisdictional claims in published maps and institutional affiliations.

\section{Submit your manuscript to a SpringerOpen ${ }^{\mathcal{O}}$ journal and benefit from:}

- Convenient online submission

- Rigorous peer review

- Open access: articles freely available online

- High visibility within the field

- Retaining the copyright to your article 